\title{
MUSULMANS ALS PORTS DE MORELLA (S. XIV)
}

Per

MANUEL GRAU I MONSERRAT

Als arxius de Morella (Els Ports) —Arxiu Històric Eclesiàstic i Històric Notarial$i$ als seus volums de protocols notarials es troben un seguit de documents en els que figuren com actors principals musulmans de València, Aragó i Catalunya. Són musulmans que mercadejaven amb els habitants dels Ports de Morella, vila de la que varen marxar quan la conquesta per Jaume l i en la que ja no en tornem a trobar com a veins. Potser el que caldria notar es l'aparició dels musulmans del Molinell (Culla) als protocols de Vilafranca segurament per la seva proximitat geogràfica.

L'Arxiu Històric Eclesiàstic (1) en l'estat actual té un doble origen: primer, la documentació d'arxiu propiament dita, que comensà a arreplegar-se al segle XIV i, segón, la Biblioteca, fundada entre 1577 i 1594 pel morellà Francesc Sancho, bisbe de Segorb, que va donar els seus llibres, segons testament de 1578, per l'arxiprestal de Morella. En 1661 es varen reunir ambdós fons i a ells s'afegiren els adquirits pel capitol eclesiàstic i les donacions de sacerdots i seglars.

En 1840, la nit del 30 al 31 de maig, mentres el setge de la ciutat pel general Espartero, al final de la primera guerra carlista, una bomba llansada pels sitiadors, va causar força destrosos en aquest Arxiu. Va poder salvar-se una bona part per alguns morellans que varen recollir tot el que varen poder i entre els anys 1847 i 1877 els va ordenar l'historiador mossén Segura Barreda tot i aprofitant la seva tasca per la seua obra magna Morella y sus aldeas (2). Després de les reformes de 1898, de l'arxiprest Zaragozà i de 1912 al 1915 de mossén Betí Bonfill, va sofrir molt els anys de la guerra civil del 1936 éssent recuperat tot el que ara es conserve per Milián Boix.

(1) MILIAN BOIX, Manuel: Morella y su Comarca, Morella, 1952, Imp. Fidel Carceller, ct. pàgs. 24-25. GRAU MONSERRAT, Manuel: Mudéjares castellonenses. «Boletin de la Real Academia de Buenas Letras de Barcelona». vol. XXIX (1961-62), 252-273, cf. pàg. 263.

(2) MORELLA, 1868, 3 vols. 
El més important de la documentació no especificament eclesiàstica són el mig miler de protocols notarials que van del 1337 al 1708, adquirits pel clero o per donacions de particulars.

Pel que fa a l'Arxiu Històric Notarial en ell s'arrepleguen els protocols de les aldees - fonamentalment Vilafranca, Cinctorres, El Forcall, La Mata i Portell-i, en menor quantitat, de Morella. Es força ric i el protocol més antic és de l'any 1307 i arriba fins l'actualitat. Ambdós, Eclesiàstic i Notarial, es complementen admirablement.

\section{Regesta documental}

1.- 1309, 10 de març (Vilafranca):

Maffomat Alondí, vei de Castelló /de Burriana/ que viu a l'alqueria de Beniconpiat, i Doménec Vicent, veí de /La Pobla/ Tornesa, deuen a Francesc de Fanlo, de Vilafranca, 30 sous reals, preu de 10 cafissos de blat que li ha comprat. A pagar per la propera festa de Santa Maria Madalena. El sarraí renuncia al seu fur. (AHNM, Domingo de La Querola, 1309).

2.- 1317, 4 de febrer (Vilafranca):

El matrimoni constituit per Pere Doménec i Sibil.la, veins de Culla, estadants al Molinell, venen unes heretats que afiten amb les de Mahomadell den Tahea, Mahomadell den Nacim i Çayt Albati. (AHM, Domingo de La Querola, 1317-1321).

3.- 1317,4 de febrer (Vilafranca):

Miquel Squerdo i familia estableixen a cens a Pere Doménec, de Culla, unes terres al Molinell, que afronten amb la propietat de Mahomadell den Tahea, la d'en Mahomadell den Nacim i la d'en Çayt Albatí. (AHNM, Domingo de La Querola, 1317-1321).

\section{4.- 1325, 15 de juliol (Morella):}

Ramon Çanou, veí de Morella, nomena procurador a Mafomat Abefanden, del Raval d'Onda, per a portar a València una càrrega de llana. (AHEM, Bartomeu Dalmenar, 1325). (GRAU: Mudéjares..., pàg. 168, doc. I).

5.- 1333, 28 de juliol (Vilafranca):

Miquel Sanxo Açnar, veí de Vilafranca, ven a Miquel Pereç, de Culla, una casa i un hort que te al Molinell i que afronta amb cases d'en Daeça, fill d'en Aliçeyt. (AHNM, Domingo de La Querola, 1332-39).

\section{6.- 1344, 21 de març (Vilafranca):}

Doménec Molinell i Martí de Lezara, veins de la Torre /en Doménec/ i Tamem Abenemelec, del Molinell, deuen a Miquel Squerdo, per compra de blat, 207 sous reals de València, a pagar per Santa Maria d'Agost pena de 5 sous diaris escolat el termini. U dels testimonis és Çayd den Ffamet, del Molinell. (AHNM, Bartomeu de La Querola, 1344).

\section{7.- 1344, 14 de maig (Vilafranca):}

Çayt ben Abdalauafit i Çayt ben Mafomet, sarraïns, i Pere Berreda, veins del Molinell, deuen a B.G. de Vilafranca, per compra de blat 20 sous i 4 diners. (AHNM, 
Miquel Bernat, 1343-45). (GRAU: Mudéjares..., pàg. 268, doc. II).

8.- 1344, 15 de maig (Vilafranca):

Jucef fill d'en Çayt, Çayt fill d'en Famet Abdala i Japhiel fill den Famet, veins del Molinell, deuen a Bernat Sanxo, 3 cafissos de blat a pagar en 10 dies. U dels testimonis és Ahen Darcesai, del Molinell. (AHNM, Antoni Spelt, 1343-72).

\section{9.- 1344, 27 de maig (Vilafranca):}

Mafomat de Cafer, del Molinell, confessa deure a B.G. de Vilafranca, per compra d'un cafís de blat, 25 sous, a pagar en el termini de deu dies, sota la pena del quart. (AHNM, Miquel Bernat, 1343-45). (GRAU: Mudéjares, pàg. 269, doc. Iii).

10.- 1362, 7 d'octubre (Vilafranca):

Miquel de Campos, del Molinell, deu a Amet Ubaquer, de la Vall d 'Uixó, 24 sous reals de València, per preu d'un ase de pèl moré, a pagar per Tots Sants, en Castelló de Burriana, en casa de Ramon Guardiola. (AHEM, Guillem Sarreal, 1359-1365).

11.- 1368, 16 de març (Morella):

Famet Amelic, d'Onda, nomenat capllevador a Miquel Margent, vei del Forcall. El sarraí renúncia al seu fur. (AHNM, Antoni Sanxo, 1368).

12.-1368, 16 de març (El Forcall):

Famet Amelic, d'Onda, revoca i anul. la el nomenament fet a favor de Miquel Marget, del Forcall, del document anterior. (AHNM, Antoni Sanxo, 1368).

13. - 1372, 16 de setembre (Morella):

Mafumat Muça, alias Borrago, de la Vall d'Uixó, reconeix deure a Ramon Guardiola, moliner, de Morella, 263 sous i 4 diners reals de València, restants d'una major quantitat, a pagar, en Morella, per Tots Sants, sota la pena del quart i 10 diners diaris de multa per quiscun dia trascorregut del termini. El sarraí ho jura per bille ille Alledi le ila allefahu hitame amel minach hua misach. Fou cancel.lat el 4 de novembre d'aquell mateix any. (AHEM, Domingo Ros, 1372).

14.- 1374, 10 de febrer (Morella):

Alí Tabal, d'Eslida, confessa deure a Nicolau Cubells, de Morella, 7 lliures i 10 sous, preu d'una mula parda, a pagar en 10 dies sota la pena del quart i 5 sous diaris de multa quiscun dia transcorregut el termini. U dels testimonis fou Caut moro vey d'Slida. (AHEM, Bernat Comte, 1374). (GRAU: Mudéjares..., pàgs. 269, doc. IV).

15.- 1374, 5 de gener (Morella):

Mafomat de Xivert, vei de la Vall d'Uixó, deu a Guillem Giner, botiguer, de Morella, 15 lliures, reals de Valéncia, preu d'un mul de pèl rogenc, a pagar abans de la festa de Pasqua de Ressurrecció. (AHEM, Domingo Ros, 1374). (GRAU: Mudéjares..., pàg. 269-270, doc. V).

\section{6.- 1382, 4 d'agost (Morella):}

Domingo de Cubells, senyor d'Herbés i sa muller Catalina, cedeixen al seu fill Esteve, 216 sous i 8 diners, reals de València, de cens anual, sobre la universitat de la /moreria/ de Mora. (AHEM, Domingo Ros, 1382). (GRAU: Mudéjares..., pàgs. 270-271, doc. VI). 
17.- 1382, 28 de setembre (Morella):

Francesc Alamany, jurisconsult morellà, en nom d'Esteve de Cubells, reb de Çayt Algordell, sarraí de Mora, 216 sous i 8 diners, pels cens que pagava dita universitat als Cubeils. (AHEM, Domingo Ros, 1382). (GRAU: Mudéjares..., pàg. 270, doc. VII).

18.- 1385, 16 de setembre (Morella):

$\mathrm{Na}$ Bonanada, usufructuaria dels béns del seu marit, Pere Gil, de Morella, peraire, he rebut d'Alí Tabal, d'Eslida, tot el que els devia axi de draps com de qualsevol mercaderia... (AHEM, Guillem Esteve, 1385). (GRAU: Mudéjares..., pàgs. 271-272, doc. VIII).

19.- 1386, 18 de setembre (Morella):

Alí Tabal, d'Eslida, deu al peraire Pere Gil, de Morella, 6 lliures i 12 sous, reals de València, per la resta $d^{\prime}$ hu drap blau e de altre vermell, a pagar abans de Nadal, sots pena de 30 sous. El sarraí renúncia al seu fur. (AHEM, Guillem Esteve, 1385). (GRAU: Mudéjares..., pàg. 272, doc. IX).

20.- 1386, 23 d'octubre (La Mata de Morella):

Pere Montmeneu, del Forcall, confessa deure a Eyup Albeyriní, alias Vermell, de Fanzara, 300 sous, preu d'un ase de pèl rogenc. A pagar: 80 sous per Nadal; 110 per Tots Sants de 1387 i la resta -altres 110 sous- per Tots Sants de 1388. Pena de 5 sous diaris passats els terminis. (AHNM, Joan Çavall, 1385-86).

21. - 1386, 21 de novembre (Barcelona):

Doménec de Bracells, mercader genovés, estadant a Barcelona, va vendre a Nicolau de Gotzems, mercader barceloní, els 204 sous reals de València, que rebia anualment de cens, pel 21 de febrer, de l'aljama delsl sarraïns de la Vall d'Uixó. (AHEM, Guillem Gaçull, 1386-89).

22.- 1386, 21 de novembre (Barcelona):

Doménec de Bracells, mercader genovés, estadant a Barcelona, ha rebut de Nicolau de Gotzems, 215 lliures, 10 seus 9 diners, moneda de Barcelona, pels quals li havia venut els 204 sous de cens anual de l'aljama de sarraïns de la Vall d'Uixó. (AHEM, Guillem Gaçull, 1386-89).

23.- 1386, 21 de novembre (Barcelona):

Azday Cresques, jueu de Barcelona, va vendre a Bonanat Català, mercader bardeloní, 186 sous i 10 diners, reals de València, sobre el censal que li pagava anualment l'aljama dels Sarraïns de la Vall d'Uixó. (AHEM, Guillem Gaçull, 1386-89).

24.- 1386, 21 de novembre (Barcelona):

Azday Cresques, jueu de Barcelona, ha rebut de Bonanat Català, mercader barceloní, 193 lliures i 9 sous, moneda de Barcelona, pels quals li va vendre el censal anterior, de l'aljama dels sarraïns de la Vall d'Uixó. (AHEM, Guillem Gaçull, 1386-89).

25.- 1386, 12 de desembre (Barcelona):

Berenguer Clariana, d'Arbúcies, diòcesi de Barcelona, ven a Nicolau de Gotzems, mercader barceloní, les 20 lliures $i 2$ sous, reals de València, que li fa de cens anual l'aljama dels sarraiins de la Vall d'Uixó, per preu de 400 lliures, 16 sous i 1 di- 
ners, moneda de Barcelona, que reb aleshores. (AHEM, Guillem Gaçull, 1386-89).

26. - 1386, 20 de desembre (Barcelona):

Astruc Abenafia, jueu de Barcelona, ven a Nicolau de Gotzems, mercader barceloní, 11 lliures i 11 sous, reals de València, d'un censal que li fa anualment l'aljama dels sarrains de la Vall d'Uixó, per preu de 240 lliures i 4 sous, moneda barcelonina, que reb aleshores. (AHEM, Guillem Gaçull, 1386-89).

27. - 1388, 6 de novembre (Les Coves de Vinromà):

Pere Sarreal, mercader, vei de Les Coves de Vinromà, procurador de Pere d'Avinyò, miles, de Vilafranca del Penedés, juntament amb en Pere Ferrer, d'Albocàsser, anomenen procurador substitut a Bernat Abrí, ciutadà de Tortosa, per a demanar a Mahoma Ataraçoní, alamí de Burriana, els drets que te al Regne de Valéncia, en Pere, Comte d'Urgell i vescomte d'Ager, que sumen 240 florins d'or d'Aragó. (AHEM, Guillem Gaçull, 1386-89).

\section{8.- 1396, 1 de febrer (Morella):}

Jaume Tous, veí de Morella, col.lector dels drets del Rei d'Aragó en la vila i aldees de Morella, fa amb Çayt Calatera i Abfalenc Alfalalig, sarrainns del lloc de Benizenet, batlia de Miravet, de l'Orde de Sant Joan de l'Hospital, composició sobre pagaments per bésties que va vendre a la fira de Morella, a canvi de 25 florins d'or d'Aragó. (AHEM, s/n., 1396). 